\title{
Visual Pigment Assignments in Regenerated Retina
}

\author{
David A. Cameron, M. Carter Cornwall, and Edward F. MacNichol Jr. \\ Department of Physiology, Boston University School of Medicine, Boston, Massachusetts 02118
}

Retinas of adult teleost fish can regenerate after injury. Two important issues regarding this phenomenon are the assembly of the regenerated retina and the neuronal images of the visual scene that the regenerated retina produces. Here we report experiments in which the visual pigment content of photoreceptors derived from native and regenerated sunfish retinas was determined by microspectrophotometry. In native retina, there is an apparently perfect correspondence between cone morphology and visual pigment content; all rods contain a middle-wavelength pigment, all single cones contain a different middle-wavelength pigment, and all double cone members contain a long-wavelength pigment. The visual pigments in regenerated rods and double cones were the same as in native retina; however, triple cones, a morphology never observed in native retina, contained the long-wavelength pigment. More-

Unlike the central structures of most adult vertebrate nervous systems, the retinas of adult teleost fish can regenerate neural cells that are lost after injury, accompanied by a recovery of visual function (Sperry, 1949, 1955) (for review, see Hitchcock and Raymond, 1991). After the surgical removal of a small patch of fish retina, the resulting wound is filled by an inward movement of the surrounding intact retina (Cameron and Easter, 1995) and by new retinal cells that are produced by a proliferative neuroepithelium that forms along the perimeter of the wound (Hitchcock et al., 1992). The synaptic organization of regenerated patches of retina resembles that observed in native retina (Hitchcock and Cirenza, 1994), suggesting that regenerated retina produces a neural image of the visual scene similar to that produced by native retina.

However, a recent investigation has revealed that the cone photoreceptor mosaic in regenerated sunfish retina is significantly different from that of native retina. In many teleosts, including green sunfish (Lepomis cyanellus), the native cone mosaic has a very orderly, rhombic pattern consisting of two morphological cone types: single cones and double cones (Eigenmann and Shafer, 1900; Cameron and Easter, 1993). This highly organized pattern is absent from the cone mosaic of regenerated retina, wherein there is an absolute excess of cones (including a relative excess of single cones), no long-range geometric pattern, and abnormal cone morphologies such as triple cones (Cameron and Easter, 1995).

Received Aug. 13, 1996; revised Oct. 10, 1996; accepted Nov. 11, 1996

This work was supported by National Institutes of Health Grants EY11160 (D.A.C.) and EY01157 (M.C.C.). We thank Laurel Carney, Gregor Jones, Vladimir Kefalov, and John White for helpful discussions and comments on this manuscript. Correspondence should be addressed to Dr. David A. Cameron, Department of Physiology, Boston University School of Medicine, 80 East Concord Street, Boston, MA 02118.

Copyright (C) 1997 Society for Neuroscience 0270-6474/97/170917-07\$05.00/0 over, although $\sim 60 \%$ of regenerated single cones contained the expected middle-wavelength pigment, all other single cones contained the long-wavelength pigment. This mismatch between morphology of regenerated single cones and their visual pigment assignment indicated the following: (1) There is a degree of independence between the mechanisms that establish cone morphology and pigment content during regeneration, which suggests that cone photoreceptor regeneration is not a straightforward recapitulation of the normal cone photoreceptor developmental plan. (2) Although anomalous, the long-wavelength single cones may enable regenerated retina to restore the native spectral sampling of the visual scene.

Key words: retina; regeneration; photoreceptors; visual pigments; microspectrophotometry; rods; cones

The aberrant cone mosaic pattern of regenerated sunfish retina suggested two independent hypotheses. First, the mechanisms underlying the construction of the cone mosaic during retinal regeneration are necessarily different from those in operation during normal retinal development. Second, the neuronal image of the visual scene produced by regenerated retina might be significantly different from that produced by native retina. In an effort to evaluate these hypotheses experimentally, we have investigated the visual pigment content of photoreceptors from native and regenerated adult green sunfish retina using microspectrophotometry (Liebman, 1972; MacNichol, 1978). We report that only the three visual pigments of native retina are present in the photoreceptors of regenerated retina. However, the assignment of these pigments to specific cone morphologies is altered, with a significant fraction of regenerated single cones containing a pigment never observed in the single cones of native retina. A hypothesis is presented that argues that this apparent mismatch in visual pigment assignment represents a compensatory mechanism by which regenerated retina attempts to recapitulate the spectral sampling of native retina.

\section{MATERIALS AND METHODS}

Adult green sunfish were purchased from Fender's Fish Hatchery and Llama Farm (Baltic, OH). Animal husbandry, anesthesia delivery, and euthanasia were as described previously (Cameron and Easter, 1993). The methodology for inducing retinal regeneration has also been described (Hitchcock et al., 1992; Cameron and Easter, 1995). Briefly, a trans-sclera excision of a $2-4 \mathrm{~mm}^{2}$ patch of dorsotemporal retina was made in anesthetized, light-adapted fish, with the opposite eye serving as an unoperated control.

Six to 16 weeks after surgery, the fish $(n=5$, standard lengths, $10.3-15.2 \mathrm{~cm}$ ) were dark-adapted for $2-3 \mathrm{hr}$, anesthetized, and killed, and the retinas harvested under infrared illumination. Harvested retinas were transferred to the following saline (in $\mathrm{mM}$ ), which was based on that used by Dearry and Burnside (1985) and Leibovic (1986): $\mathrm{NaCl} 116.4 ; \mathrm{KCl} 5.4$; $\mathrm{Na}_{2} \mathrm{HPO}_{4}$ 1.0; $\mathrm{MgSO}_{4}$ 0.8; $\mathrm{CaCl}_{2}$ 1.8; $\mathrm{NaHCO}_{3}$ 24.0; glucose 25.5; 
HEPES 3.0; bovine serum albumin $0.1 \mathrm{mg} / \mathrm{ml}$; MEM vitamins $(100 \times$, Sigma, St. Louis, MO), $0.5 \mathrm{ml} / 100 \mathrm{ml}$; MEM amino acids $(50 \times$, Sigma), $1.0 \mathrm{ml} / 100 \mathrm{ml} ; \mathrm{pH} 7.4-7.5$, at room temperature $\left(20-23^{\circ} \mathrm{C}\right)$. The patches of regenerated retina were identified in eye cups, as described previously (Hitchcock and Cirenza, 1994), and were cut away from surrounding intact retina with a microknife. The corresponding dorsotemporal region of the unoperated eye was located using ocular landmarks (Cameron and Easter, 1993; Cameron, 1996), and photoreceptors derived from this area were used for most control experiments, although there was no apparent dependence of visual pigment content on retinal location.

Photoreceptors were isolated from retinal fragments, including regenerated patches, by gently chopping the fragments with the microknife. The isolated photoreceptors were suspended in a saline-filled, $70-\mu \mathrm{m}$ thick chamber bound by two glass coverslips. Spectroscopic measurements of visual pigment absorption spectra were made with a computercontrolled, photon-counting microspectrophotometer (schematized in MacNichol, 1978, p 201; Levine and MacNichol, 1985). Briefly, a rectangular beam of linearly polarized light, $\sim 1 \times 3 \mu \mathrm{m}$, focused on the outer segments of solitary photoreceptors lying on the bottom floor of the chamber was used to derive optical density (OD) measurements in the range of $400-750 \mathrm{THz}(750-400 \mathrm{~nm})$, in $5 \mathrm{THz}$ bins. The plane of polarization was perpendicular to the long dimension of the rectangular stimulus image.

For each incident frequency, the OD of an outer segment was measured. OD was defined as:

$$
\mathrm{OD}=\log _{10} I_{0} / I_{t},
$$

where $I_{0}$ is the number of photons incident on the photomultiplier in the absence of a sample (in this case, a photoreceptor's outer segment, wherein the visual pigment molecules reside) (Fig. 1, insets), and $I_{\mathrm{t}}$ is the photon count incident on the photomultiplier after the light passes through the outer segment. For the $I_{\mathrm{t}}$ measurement, the rotary microscope stage of the microspectrophotometer was adjusted so that the stimulus beam (at frequency $400 \mathrm{THz}$ ) was placed entirely within the outer segment area, with the long dimension of the stimulus rectangle parallel to the long axis of the outer segment. To minimize visual pigment bleaching, the chambers were illuminated with infrared light and were monitored with an infrared-sensitive television camera. The output of the television camera was saved onto video tape.

A single scan across the entire frequency range was completed in $\sim 1$ sec and for a given cell, the average of 10 such scans was used to derive an OD spectrum ("absorbance" spectrum) (Cornwall et al., 1984). All OD spectra were calculated and saved on-line by computer. The collected OD spectra for each photoreceptor morphology/spectral type were then averaged, normalized, and fitted by a least-squares algorithm (Marquardt-Levenberg) with a visual pigment absorbance template. The template was a frequency-dependent eighth-order polynomial:

$$
\mathrm{OD}=\Sigma\left(a_{n} \times\left[\left(F-F_{\max }\right) / F_{\max }\right]^{n}\right),
$$

where $F$ is the frequency, $F_{\max }$ is the frequency at maximum OD, and the coefficients $a_{0}-a_{8}$ are $1.0000,0.02563,-44.5532,155.063,567.606$, $-5543.03,10003.9,59338.0$, and -208122 . This template was empirically derived from the absorption spectra of the vitamin $\mathrm{A}_{2}$ (3-dehydroretinal)based visual pigment of Necturus maculosa rods, ranging from 0.83 and 1.11 times $F_{\max }$ (G. Jones, unpublished observations). To match the standard convention, the data are illustrated in terms of wavelength rather than frequency.

\section{RESULTS}

Photoreceptors from native and regenerated retinas were analyzed 6-16 weeks after surgery, which is after the interval during which regenerated retina fills the wound (Hitchcock et al., 1992). For all data described below, there was no dependence on survival time after surgery, nor was there any dependence on eye or body size.

\section{Native retina}

The photoreceptor morphologies isolated from native retina were rods, single cones, and double cones, and each was readily identifiable (Fig. 1, line drawings). A summary of the spectral and morphological characteristics of photoreceptors is presented in

\begin{tabular}{|c|c|c|c|c|}
\hline Cell type & $n$ & $\begin{array}{l}\lambda_{\max } \\
(\mathrm{nm})\end{array}$ & $\begin{array}{l}\text { Pigment density } \\
(\mathrm{OD} / \mu \mathrm{m})\end{array}$ & $\begin{array}{l}\text { Outer } \\
\text { segment } \\
\text { length }(\mu \mathrm{m})\end{array}$ \\
\hline Rod (nat) & 21 & $527 \pm 1$ & $0.013 \pm 0.0018$ & $27.2 \pm 0.5$ \\
\hline Rod (reg) & 30 & $526 \pm 1$ & $0.018 \pm 0.0040$ & $25.6 \pm 0.8$ \\
\hline SC (nat) & 26 & $532 \pm 1$ & $0.012 \pm 0.0013$ & $8.2 \pm 0.9$ \\
\hline SC (reg, grn) & 19 & $534 \pm 1$ & $0.013 \pm 0.0010$ & $8.0 \pm 1.0$ \\
\hline $\mathrm{SC}$ (reg, red) & 13 & $622 \pm 2$ & $0.011 \pm 0.0034$ & $8.4 \pm 1.3$ \\
\hline DC (nat) & 44 & $620 \pm 1$ & $0.011 \pm 0.0019$ & $13.4 \pm 0.8$ \\
\hline DC (reg) & 28 & $623 \pm 1$ & $0.014 \pm 0.0014$ & $10.9 \pm 0.7$ \\
\hline TC (reg) & 6 & $618 \pm 3$ & $0.010 \pm 0.0013$ & $10.7 \pm 1.6$ \\
\hline
\end{tabular}
Table 1, and averaged absorption spectra for each morphology are $\overline{\text { All data are mean } \pm 1 \text { SEM. SC, Single cones; DC, double cones; TC, triple cones; }}$ nat, native retina; reg, regenerated retina; grn, middle-wavelength visual pigment; red, long-wavelength visual pigment; $\lambda_{\max }$, wavelength of maximum absorption; OD, optical density.

illustrated in Figure 1. Rods always contained a middlewavelength ("green") visual pigment with peak absorption at $527 \pm 1 \mathrm{~nm}(n=21 ;$ mean \pm SEM) (Fig. 1a, open symbols $)$. All double cone members contained a long-wavelength ("red") visual pigment with peak absorption at $620 \pm 1 \mathrm{~nm}(n=44)$ (Fig. $1 b$, open symbols). All single cones contained a middle-wavelength visual pigment different from that found in rods, with peak absorption at $532 \pm 1 \mathrm{~nm}(n=26)$ (Fig. 1c, open symbols). The absorption spectra for all photoreceptors were consistent with visual pigments composed of an opsin linked to a vitamin $\mathrm{A}_{2}$ chromophore (Fig. 1, solid lines). The absolute densities of the visual pigments in rods, double cone members, and single cones were $0.013 \pm 0.0018,0.011 \pm 0.0019$, and $0.012 \pm 0.0013 \mathrm{OD} / \mu \mathrm{m}$, respectively, similar to the values reported previously for amphibian (Hárosi, 1975) and primate photoreceptors (Bowmaker et al., 1978). The ostensibly perfect correspondence between photoreceptor morphology and visual pigment content matched that reported in an earlier investigation of adult green sunfish photoreceptors (Dearry and Barlow, 1987). There was no evidence of photoreceptors containing a short-wavelength ("blue") visual pigment.

\section{Regenerated retina}

The photoreceptor morphologies isolated from regenerated retina were rods, single cones, double cones, and triple cones (Table 1 , summary statistics). The visual pigments of regenerated rods and double cone members were not different from their respective morphological counterparts of native retina. Regenerated rods always contained a middle-wavelength, vitamin $\mathrm{A}_{2}$-based visual pigment with peak absorption at $526 \pm 1 \mathrm{~nm}(n=30)$ (Fig. $1 a$, solid symbols), and both regenerated double cone members always contained a long-wavelength, vitamin $\mathrm{A}_{2}$-based visual pigment with peak absorption at $623 \pm 1 \mathrm{~nm}(n=28)$ (Fig. $1 b$, filled symbols). The absolute densities of the visual pigments in regenerated rods $(0.018 \pm 0.0040 \mathrm{OD} / \mu \mathrm{m})$ and double cone members $(0.014 \pm 0.0014 \mathrm{OD} / \mu \mathrm{m})$ were not significantly different from the corresponding values for native retina ( $p=0.23$ and 0.15 , respectively; independent $t$ test). Each triple cone member for which absorption spectra were derived ( $n=6$ members from 4 triple cones) contained a long-wavelength, vitamin $\mathrm{A}_{2}$-based visual pigment with peak absorption at $618 \pm 3 \mathrm{~nm}$ and a pigment density of $0.010 \pm 0.0013 \mathrm{OD} / \mu \mathrm{m}$ (Fig. 2). As in native retina, there was 


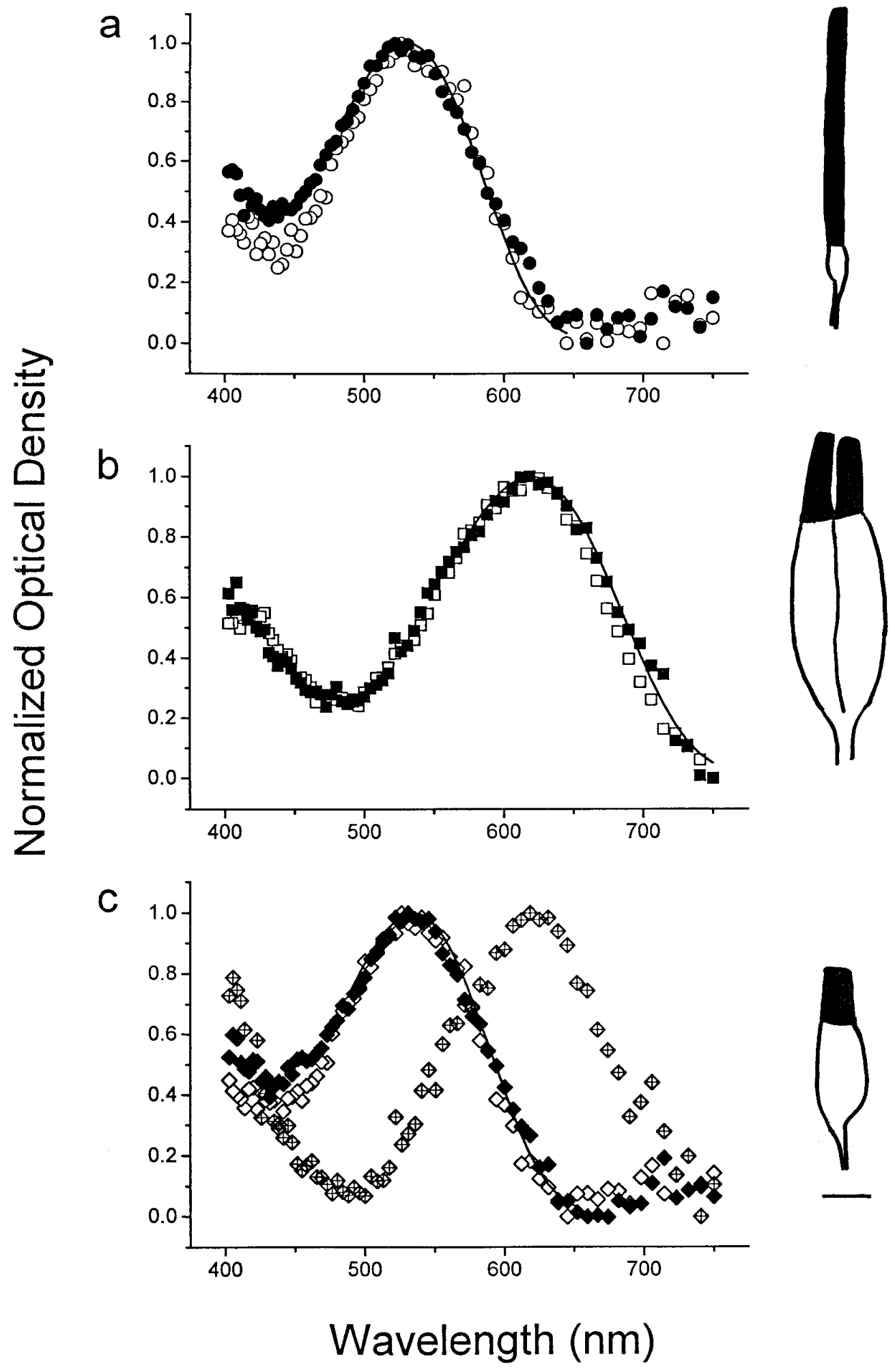

Figure 1. Absorption spectra of photoreceptors from native and regenerated green sunfish retina. Data are plotted as normalized average OD, as a function of wavelength (see Materials and Methods). $a$, Absorption spectra of rods from native $(n=15$, open circles $)$ and regenerated retina $(n=28$, solid circles). The averaged data from native retina are fit by the vitamin $A_{2}$-based visual pigment absorption template (solid line; see Materials and Methods). The template curve peaks at $526 \mathrm{~nm}$. $b$, Absorption spectra of double cone members from native $(n=10$, open squares) and regenerated retina ( $n=17$, solid squares). The vitamin $\mathrm{A}_{2}$-based visual pigment template is fit to the native double cone data and peaks at $620 \mathrm{~nm}$ (solid line).c, Absorption spectra of single cones from native $(n=10$, open diamonds) and regenerated retina. Unlike single cones from native retina, the data for regenerated single cones fall within two distinct spectral populations: a "green" group ( $n=10$, solid diamonds) and a "red" group $(n=10$, crossed diamonds). The vitamin $\mathrm{A}_{2}$-based visual pigment template is fit to the native single cone data and peaks at $532 \mathrm{~nm}$ (solid line). Note how the "red" spectrum closely matches that of double cones (compare $b$ ). Insets, Line drawings of a rod $(a)$, double cone $(b)$, and single cone (c) from regenerated retina traced from the videotape record. The outer segments are denoted as the solid profiles. Scale bar, $5 \mu \mathrm{m}$.

no evidence of any photoreceptors containing a short-wavelength visual pigment.

Unlike the situation in native retina, there were two distinct spectral populations of single cones derived from regenerated retina. One of these populations ( $\sim 60 \%$ of the total sample) contained a visual pigment that was not significantly different from that found in single cones derived from native retina: a middle-wavelength, vitamin $\mathrm{A}_{2}$-based visual pigment with peak absorption at $534 \pm 1 \mathrm{~nm}(n=19)$ Fig. $1 c$, solid symbols $)$. The other population contained a visual pigment with an absorption spectrum similar to that normally associated with double cones: a long-wavelength, vitamin $\mathrm{A}_{2}$-based visual pigment with peak absorption at $622 \pm 2 \mathrm{~nm}(n=13)$ (Fig. $1 c$, crossed symbols). The visual pigment densities of the "green" and "red" single cones were $0.013 \pm 0.0010$ and $0.011 \pm 0.0034 \mathrm{OD} / \mu \mathrm{m}$, respectively. Because these values were not significantly different from the 


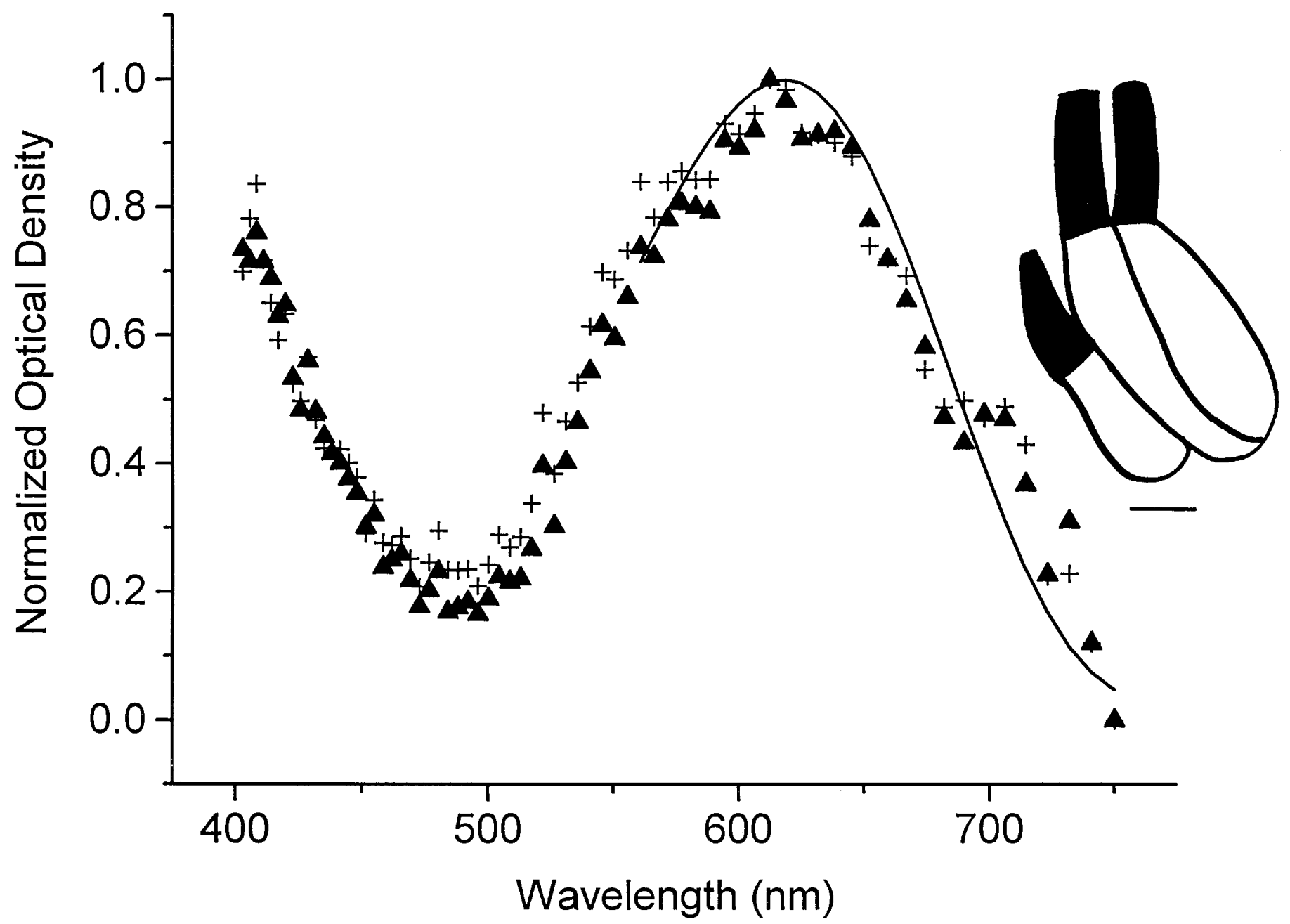

Figure 2. Normalized averaged absorption spectra of triple cone members from regenerated green sunfish retina. The data represent the average of all sampled triple cone members $(n=6$, triangles $)$, which were derived from four triple cones, and the averaged data of the one triple cone for which absorption spectra could be derived from all three members (plus signs). The vitamin $\mathrm{A}_{2}$-based visual pigment template peaks at $619 \mathrm{~nm}$ (solid line). Inset, Line drawing of a triple cone traced from the videotape record. Scale bar, $5 \mu \mathrm{m}$.

visual pigment density of single cones in native retina ( $p=0.40$ and 0.81 , respectively), it was concluded that the two different spectral populations of regenerated single cones did not arise from differences in pigment-independent optical properties of the outer segments or from differences in visual pigment incorporation at the outer segment disk membranes.

The absorption spectra of the long-wavelength visual pigments derived from all double cones, triple cones, and the regenerated "red" single cones were superimposable over much of their range, indicating that the spectra were likely to have been derived from the same visual pigment (Fig. 3). The dip in the "red" single cone spectrum at middle wavelengths (Fig. 1c) may be attributable to artifactual light scattering or the lack of a near-zero baseline at long wavelengths (i.e., near $750 \mathrm{~nm}$ ). It was unlikely that the "red" population of regenerated single cones was derived from split double cones, because (1) single cones with a long-wavelength visual pigment were never observed from native retina in this or an earlier investigation (Dearry and Barlow, 1987), and (2) the outer segment lengths of these single cones were inconsistent with the corresponding value for double cone members (Table 1).

\section{DISCUSSION}

\section{Retinal regeneration and development: similarities and differences}

An open question regarding the regeneration of neural structures in adult vertebrates is whether, and to what extent, the regenerative processes are a recapitulation of the mechanisms that control the assembly of such structures during development. The results from recent experimental investigations of adult teleost retina regeneration have provided insight to this issue, with the cumulative evidence suggesting that regenerative processes share many similarities to developmental mechanisms. The radial distribution of defined neuronal subtypes, as well as the synaptic organization and stratification patterns within the plexiform layers, resembles that of native retina (Braisted and Raymond; 1992; Hitchcock et al., 1992; Hitchcock and Cirenza, 1994; Hitchcock and VanDeRyt, 1994; Cameron and Easter, 1995). Furthermore, morphological and molecular characteristics of regenerative neuroepithelia match that of the neuroepithelium that generates retinal neurons during normal growth (Hitchcock et al., 1992, 1996; Levine et al., 1994). 


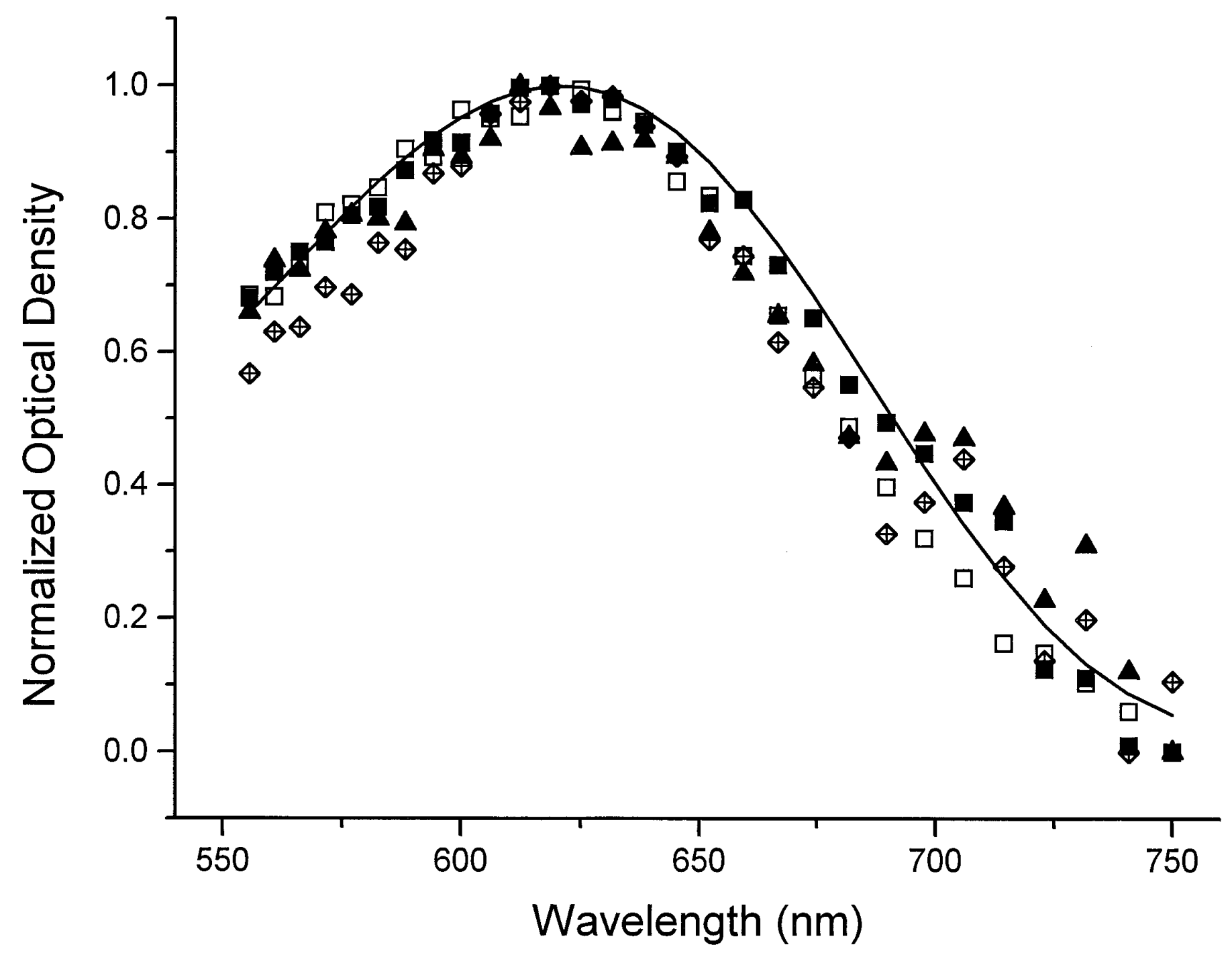

Figure 3. Normalized averaged absorption spectra for all "red" photoreceptors from native and regenerated green sunfish retina. The plotted data illustrate absorption spectra derived from native double cones (open squares), regenerated double cones (solid squares), "red" regenerated single cones (crossed diamonds), and triple cones (triangles) near their common peak of $\sim 620 \mathrm{~nm}$. The similarity of the spectra argues that each photoreceptor morphology contained the same long-wavelength visual pigment. The data are superimposed with the vitamin $\mathrm{A}_{2}$-based visual pigment template used to fit the native double cone data of Figure $1 b$ (solid line).

Some studies also provide evidence, however, that retinal regeneration is not a straightforward recapitulation of retinal development. First, it is possible to selectively regenerate photoreceptors without a concomitant production of new inner retinal neurons (Braisted et al., 1994). Second, the regenerative assembly and organization of new neuronal material occur at a much faster rate than during normal development (Hitchcock and Cirenza, 1994). Third, the spatial pattern of neuronal mosaics across the regenerated retinal sheet is often significantly different from those established during development, with regenerated cellular mosaics characterized by higher cellular densities and/or abnormal spatial patterns (dopaminergic cells: Hitchcock and VanDeRyt, 1994; cone photoreceptors: Cameron and Easter, 1995).

The results from the present study argue that the regeneration of cone photoreceptors is not a simple recapitulation of developmental processes. Specifically, $\sim 40 \%$ of all single cones in regenerated green sunfish retina are assigned a visual pigment that is never observed in single cones of native retina. Although our methodology is likely unable to detect low levels of a secondary pigment(s) in the outer segments (see Makino and Dodd, 1996), the density of the anomalous visual pigment in these single cones (Table 1) indicates that the anomalous pigment defines the spectral nature of the cone. Thus, there is a significant "mismatch" between the single cone morphology and visual pigment content. Furthermore, that two different visual pigments can be assigned to the equivalent cone morphology indicates a degree of independence between the mechanisms that regulates these two phenotypic attributes of vertebrate photoreceptors during regeneration, an independence that is not overtly manifest during normal development.

In contrast, multiple-cone morphologies in both native and regenerated retina are consistently assigned to the longwavelength visual pigment. Although triple cones are never observed in native L. cyanellus retina (Cameron and Easter, 1993), our results suggest that during both development and regeneration of green sunfish retina, there is a seemingly perfect correla- 
a

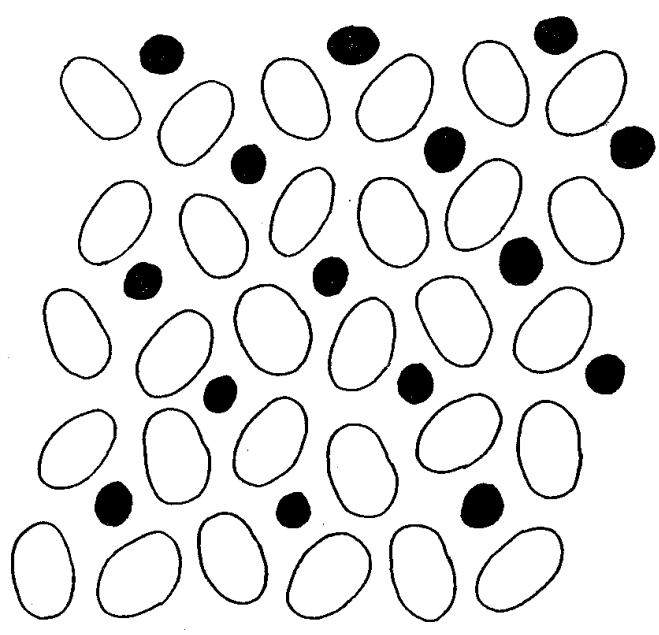

b
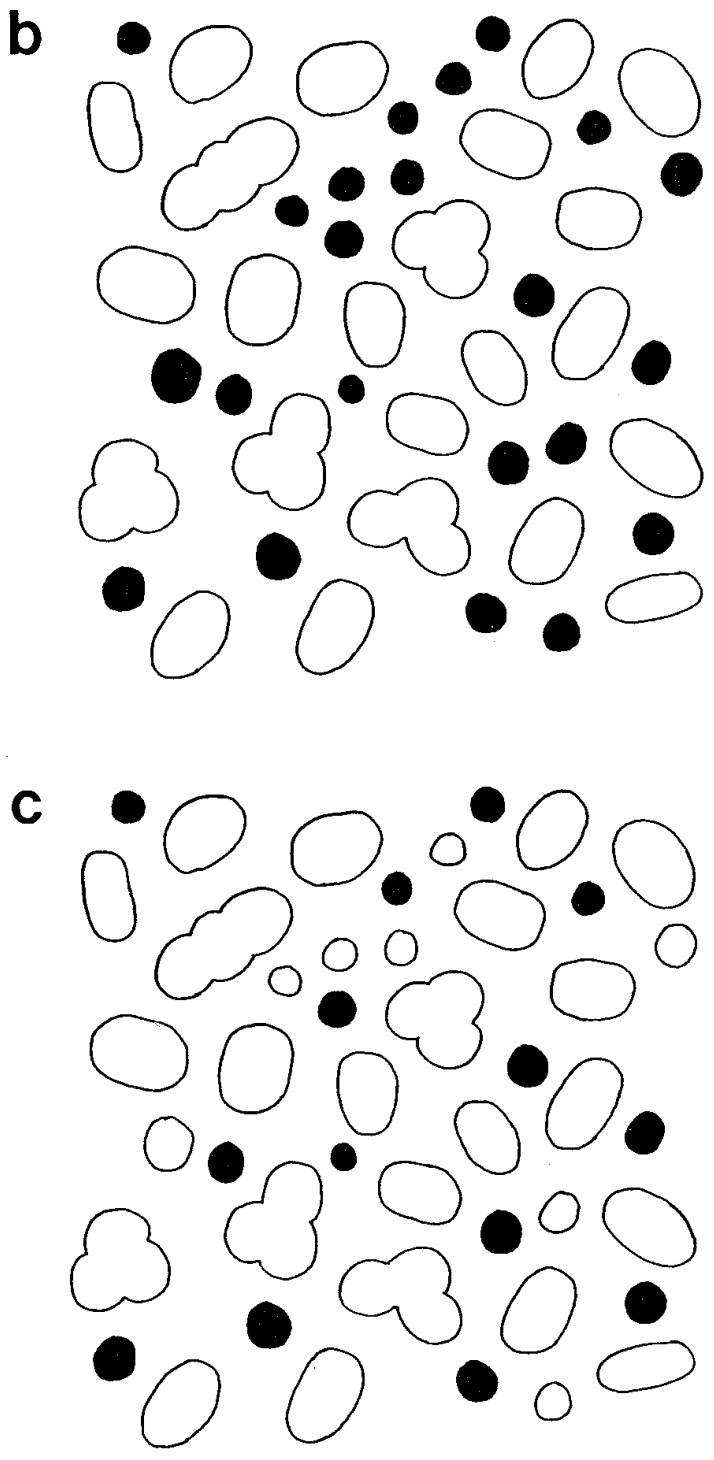

Figure 4. Recovery of appropriate spectral sampling in regenerated green sunfish retina; a hypothesis to explain the mismatch phenomenon between the single cone morphology and visual pigment content. $a$, The two-dimensional pattern of double cone (elliptical profiles) and single cone (circular profiles) photoreceptors across native sunfish retina. All double tion between the mechanisms that regulate multiple-cone morphology and opsin expression. Determination of whether this regulatory correlation is evident at, or near, the time of birth of multiple cones (Raymond et al., 1995) awaits future study.

The molecular mechanisms that regulate opsin expression and morphogenesis of photoreceptors during retinal regeneration and normal retinal growth are largely unknown. However, there is mounting evidence that cell-cell interactions, including direct cell-cell contacts, play an important role in photoreceptor induction (Harris and Messersmith, 1992; Adler, 1993). In fish, double cones apparently can be formed by the fusion of two individual, but not necessarily sibling, cone cells (Scholes, 1976; Evans and Fernald, 1993; Cameron and Easter, 1995), indicating that direct cone-cone contacts might regulate cone phenotype. Photoreceptor-photoreceptor interactions have also been implicated in the development of spatial and chromatic cone mosaic patterns in fish retina (Cameron and Easter, 1995; Raymond et al., 1995; Stenkamp et al., 1996), and such interactions may also contribute to the spatial and chromatic pattern of cones in regenerated retina.

\section{Hypothesized adaptive significance for the anomalous "red" single cones}

Of what physiological consequence are the "red" single cones in regenerated retina? We present the following hypothesis to provide an adaptive significance for the mismatch phenomenon: restoration of the native spectral sampling of the visual scene. In native green sunfish retina, the "red:green" cone ratio is 4:1 (2 double cones: 1 single cone), thus producing a spectral sampling of the visual scene that is "red"-dominant (Fig. 4a) (Cameron and Easter, 1993). If all single cones in regenerated retina, of which there is both a relative and an absolute excess, contained the middle-wavelength visual pigment, the "red:green" cone ratio would drop to $\sim 2.6: 1[($ double cones $\times 2)+$ (triple cones $\times$ 3):( single cones $\times 1$ ), from Cameron and Easter, 1995, p 2264]. Such spectral sampling is qualitatively different from that of native retina (Fig. 4b). However, if, as suggested by the present results, $\sim 40 \%$ of all regenerated single cones contain the "red" visual pigment, this ratio becomes $4.6: 1$, which could represent a spectral mosaic that is qualitatively more similar to that of native retina (Fig. 4c). Future determination of the precise spatial distribution of visual pigments across regenerated retina will require a different methodology, such as the nitro blue tetrazolium technique (Marc and Sperling, 1977) or in situ hybridization of visual pig-

\footnotetext{
$\leftarrow$

cones contain the "red" visual pigment (open profiles), and all single cones contain the "green" visual pigment (solid profiles). This mosaic pattern is traced from previously published data (Cameron and Easter, 1993, their Fig. $2 c$ ). Note how this spectral sampling scheme is "red"-dominant. $b$, Model spectral sampling scheme of regenerated retina, assuming that all single cones contain the "green" visual pigment (solid circular profiles). All double and triple cones (the latter represented by tripodal and linear triplet profiles) contain the "red" visual pigment (open profiles). Note how this spectral sampling scheme has a greater "green" component than native retina $(a)$. This cone mosaic pattern is traced from a tangential section through regenerated green sunfish retina (Cameron and Easter, 1995, their Fig. 13a). c, Hypothetical spectral sampling scheme of regenerated retina, based on the results of this study; $\sim 40 \%$ of all single cones contain the "red" visual pigment (open circular profiles). The "red" single cones have been distributed uniformly across the section. The hypothesis argues that this spectral sampling scheme represents a qualitatively better "red/ green" match to native retina than does the condition in which all regenerated single cones contain the "green" visual pigment $(b)$ and, thus, may provide a restoration of the appropriate spectral sampling of the visual scene (see Discussion).
} 
ment transcripts. Such investigations might also provide clues to the nature of the signals that regulate the spatial and chromatic pattern of the regenerated cone mosaic.

The outer segments of regenerated photoreceptors contain visual pigment molecules at a density that is not significantly different from that of native photoreceptors (Table 1). The ability of regenerated photoreceptors to absorb incident photons thus is likely to be similar to that of native photoreceptors. Additionally, earlier studies have reported that regenerated photoreceptors have synaptic apparatuses that are virtually identical to those observed in native retina (Hitchcock and Cirenza, 1994; Cameron and Easter, 1995). Together with the above hypothesis, these results indicate that an approximately normal neural representation of the visual scene's spectral content might be constructed by regenerated teleost retina.

Within the framework of the above hypothesis, the anomalous "red" single cones represent the outcome of a compensatory strategy, a strategy adopted by regenerated retina to impose a "red"-dominance on a cone mosaic that contains an excess of the nominally "green" cone morphology. The significance of longwavelength sensitivity for aquatic daylight vision, specifically, as a mechanism for enhancing the visual contrast of objects against the short- and middle-wavelength background light common to underwater environments, has been addressed previously (Lythgoe, 1968; Easter, 1975), and many freshwater teleosts have "red"dominant retinas (Levine and MacNichol, 1979). The critical nature of long-wavelength sensitivity to such species is reinforced by the recovery of the "red" cone mosaic in regenerated green sunfish retina; the "dilution" of long-wavelength sensitivity by the addition of middle-wavelength ("green") cones is apparently maladaptive for the green sunfish's visual environment.

\section{Summary and conclusions}

The photoreceptors of regenerated retina only contain visual pigments normally found in native retina. However, many regenerated single cones contain the visual pigment normally associated only with double cones. This mismatch between cone morphology and visual pigment content suggests that photoreceptor regeneration is not a straightforward recapitulation of normal development. However, although anomalous, these "red" single cones may serve to provide regenerated retina with the appropriate spectral sampling of the visual scene.

\section{REFERENCES}

Adler R (1993) Determination of cellular types in the retina. Invest Ophthalmol Vis Sci 34:1677-1682.

Bowmaker JK, Dartnall HJA, Lythgoe JN, Mollon JD (1978) The visual pigments of rods and cones in the rhesus monkey, Macaca mulatta. J Physiol (Lond) 274:329-348.

Braisted JE, Raymond PA (1992) Regeneration of dopaminergic neurons in goldfish retina. Development 114:913-919.

Braisted JE, Essman TF, Raymond PA (1994) Selective regeneration of photoreceptors in goldfish retina. Dev Brain Res 76:221-232.

Cameron DA (1996) Asymmetric retinal growth: evidence for regulation by a retinotopic mechanism. Vis Neurosci 13:493-500.

Cameron DA, Easter Jr SS (1993) The cone photoreceptor mosaic of the green sunfish (Lepomis cyanellus). Vis Neurosci 10:375-384.

Cameron DA, Easter Jr SS (1995) Cone photoreceptor regeneration in adult fish retina: phenotypic determination and mosaic pattern formation. J Neurosci 15:2255-2271.

Cornwall MC, MacNichol Jr EF, Fein A (1984) Absorptance and spec- tral sensitivity measurements of rod photoreceptors of the tiger salamander, Ambystoma tigrinum. Vision Res 11:1651-1659.

Dearry A, Barlow Jr RB (1987) Circadian rhythms in the green sunfish retina. J Gen Physiol 89:745-770.

Dearry A, Burnside B (1985) Dopamine inhibits forskolin- and 3-isobutyl-1-methylxanthine-induced dark-adaptive retinomotor movements in isolated teleost retinas. J Neurochem 44:1753-1763.

Easter Jr SS (1975) Retinal specialisations for aquatic vision: theory and facts. In: Vision in fishes (Ali MA, ed), pp 609-617. New York: Plenum.

Eigenmann CH, Shafer GD (1900) The mosaic of single and twin cones in the retina of fishes. Am Nat 34:109-118.

Evans BI, Fernald RD (1993) Retinal transformation at metamorphosis in the winter flounder (Pseudopleuronectes americanus). Vis Neurosci 10:1055-1064.

Hárosi FI (1975) Absorption spectra and linear dichroism of some amphibian photoreceptors. J Gen Physiol 66:357-382.

Harris WA, Messersmith SL (1992) Two cellular inductions involved in photoreceptor determination in the Xenopus retina. Neuron 9:357-372.

Hitchcock PF, Cirenza P (1994) Synaptic organization of regenerated retina in the goldfish. J Comp Neurol 343:609-614.

Hitchcock PF, Raymond PA (1991) Retinal regeneration. Trends Neurosci 15:103-108.

Hitchcock PF, VanDeRyt JT (1994) Regeneration of the dopamine-cell mosaic in the retina of the goldfish. Vis Neurosci 10:209-218.

Hitchcock PF, Lindsey Myrh KJ, Easter Jr SS, Mangione-Smith R, Jones DD (1992) Local regeneration in the retina of the goldfish. J Neurobiol 23:187-203.

Hitchcock PF, Macdonald RE, VanDeRyt JT, Wilson SW (1996) Antibodies against Pax6 immunostain amacrine and ganglion cells and neuronal progenitors, but not rod recursors, in the normal and regenerating retina of the goldfish. J Neurobiol 29:399-413.

Leibovic KN (1986) A new method of non-enzymatic dissociation of the Bufo retina. J Neurosci Methods 15:301-306.

Levine EM, Hitchcock PF, Glasgow E, Schechter N (1994) Restricted expression of a new paired-class homeobox gene in normal and regenerating adult goldfish retina. J Comp Neurol 348:596-606.

Levine JS, MacNichol Jr EF (1979) Visual pigments in teleost fishes: effects of habitat, microhabitat and behavior on visual system evolution. Sensory Proc 3:95-131.

Levine JS, MacNichol Jr EF (1985) Microspectrophotometry of primate photoreceptors: art, artifact, and analysis. In: The visual system (Fein A, Levine JS, eds), pp 73-78. New York: Liss.

Liebman PA (1972) Microspectrophotometry of photoreceptors. In: Handbook of sensory physiology, Vol VII, Part I (Dartnall HJA, ed), pp 481-528. Berlin: Springer.

Lythgoe JN (1968) Visual pigments and visual range underwater. Vision Res 8:997-1011.

MacNichol EF (1978) A photon-counting microspectrophotometer for the study of single vertebrate photoreceptor cells. In: Frontiers of visual science (Cool SJ, Smith EL, eds), pp 194-208. Berlin: Springer.

Makino CL, Dodd RL (1996) Multiple visual pigments in a photoreceptor of the salamander retina. J Gen Physiol 108:27-34.

Marc RE, Sperling HG (1977) Chromatic organization of primate cones. Science 196:454-456.

Raymond PA, Barthel LK, Curran GA (1995) Developmental patterning of rod and cone photoreceptors in embryonic zebrafish. J Comp Neurol 359:537-550.

Scholes JW (1976) Neuronal connections and cellular arrangement in the fish retina. In: Neural principles in vision (Zettler F, Weiler R, eds), pp 63-93. Berlin: Springer.

Sperry RW (1949) Reimplantation of eyes in fishes (Bathygobius soporator) with recovery of vision. Soc Exp Biol Med Proc 71:80-81.

Sperry RW (1955) Functional regeneration in the optic system. In: Regeneration in the central nervous system (Windle WF, ed), pp 66-76. Springfield, IL: Thomas.

Stenkamp DL, Hisatomi O, Barthel LK, Tokunaga F, Raymond PA (1996) Temporal expression of rod and cone opsins in embryonic goldfish retina predicts the spatial organization of the cone mosaic. Invest Ophthalmol Vis Sci 37:363-376. 